\title{
ĐÁNH GIÁ HỆ THỐNG THANG ĐIỂM TSS VÀ BRIXIA TRONG X-QUANG NGỰC Ở BÊ̂NH NHÂN MẮC BỆNH COVID 19
}

\begin{abstract}
Hoàng Thụy Đoa
TÓM TẮT

Mục tiêu: Áp dụng 2 hệ thống thang điểm TSS (Total Severity Score) và Brixia trong hình ảnh Xquang ngực để đánh giá suy hô hấp cấp nặng do bệnh Covid-19. Đối tượng và phương pháp: Nghiên cứu trên 128 bệnh nhân nằm viện vì bệnh Covid-19, có ít nhất 2 lần chụp $X$-quang phổi lúc vào viện và lúc ra viện hoặc chuyển viện. Kết quả: Hai bác sĩ chẩn đoán hình ảnh đọc phim X-quang phổi theo 2 hệ thống thang điểm TSS và Brixia có chỉ số tương hợp tốt kappa lần lượt là 0,734 và 0,668 . Nhưng khi so sánh 2 hệ thống thang điểm TSS và Brixia thì chỉ tương hợp ở mức trung bình với kappa 0,584 do hai hệ thống có số điểm tối đa khác nhau ( 8 và 18 điểm). Thang điểm TSS bỏ sót nhiều bệnh ở mức độ vừa và nặng có nhiều nguy cơ tử vơng. Kết luận: Hệ thống thang điểm để đánh giá $X$-quang phổi là cần thiết trong theo dõi điều trị Covid-19. Thang điểm TSS dễ đánh giá nhưng có thể bỏ sót các bệnh nhân vừa và nặng có nhiều nguy cơ tử vong.
\end{abstract}

Tư khóa: Covid-19, Thang điểm TTS, Thang điểm Brixia, phim X-quang phổi.

\section{SUMMARY}

EVALUATION TWO CHEST X-RAY TSS AND BRIXIA SCORING SYSTEMS IN COVID-19 PATIENTS

Objectives: Applying the TSS and Brixia chest $\mathrm{X}$-ray score systems to assess severe acute respiratory failure due to Covid-19. Subjects and methods: Analytic prospective study. Study on 128 hospitalized patients with Covid-19 who had at least 2 x-rays at the time of admission and at discharge or transfer to other hospital. Results: Two radiologists read chest X-ray films according to 2 systems for TSS and Brixia scores. Two radiologists had good agreement index when scoring according to TSS and Brixia system (kappa 0.734 and 0.668). But when comparing those two systems between the two radiologists, the agreement level was average (kappa 0.584) because the two systems have different maximum scores ( 8 and 18 points). The TSS scoring system again missed many moderate and severe diseases with high risk of death. Conclusion: A scoring system is needed to evaluate chest X-rays especially during the Covid-19 pandemic. The TSS scoring system is easy to evaluate but easily misses the moderate and severe patients who have a higher risk of death than the Brixia system.

Keywords: Scoring system, chest X-ray, TSS (total severity score), Brixia score

\section{*Bệnh Viện Nhật Tân}

Chịu trách nhiệm chính: Hoàng Thụy Đoan Trâm

Email: Htdt173@gmail.com

Ngày nhận bài: 25.10.2021

Ngày phản biện khoa học: 22.12.2021

Ngày duyệt bài: 29.12.2021

\section{I. ĐĂT VẤN ĐỀ}

Coronavirus là một họ vi rút có thể gây ra các bệnh như cảm lạnh thông thường, hội chứng hô hấp cấp tính nặng (SARS) và hội chứng hô hấp Trung Đông (MERS). Bệnh Covid-19 được phát hiện lần đâu tại Vũ Hán, Trung Quốc. Đây là một bệnh gây hội chứng hô hấp cấp tính nặng thứ 2 (SARS-CoV-2). Vào tháng 3 năm 2020, Tổ chức Y tế Thế giới (WHO) tuyên bố sự bùng phát Covid-19 là một đại dịch cho đến ngày hôm nay. Bệnh Covid-19 đã xuất hiện nhiều biến chủng như Alpha xuất hiện ở Anh, Bêta ở Nam Phi, Gamma ở Brazil, Delta ở Ấn Đô và gần đây nhất là biến thể Omicron (B.1.1.529) đang xuất hiện ở nhiều nước [1].

Các dấu hiệu và triệu chứng của bệnh do Coronavirus 2019 (Covid-19) có thể xuất hiện từ 2 đến 14 ngày sau khi tiếp xúc. Các dấu hiệu phổ biến có thể bao gồm: sốt, ho, mệt mỏi. Các triệu chứng ban đâu có thể bao gồm mất vị giác hoặc khứu giác. Các triệu chứng khác có thể bao gồm: thở dốc hoặc khó thở, đau cơ, ớn lạnh, viêm họng, sổ mũi, đau đầu, tức ngực, mắt đỏ, buồn nôn, nôn mửa, tiêu chảy, phát ban... Triệu chứng có thể từ rất nhẹ đến rất nặng. Nhưng một số người lại có các triệu chứng Covid-19 trong hơn 4 tuần sau khi được chẩn đoán, tình trạng này được gọi là tình trạng sau Covid-19 hoặc Covid-19 kéo dài. Một số trẻ em có thể gặp hội chứng viêm đa hệ, có thể ảnh hưởng đển một số cơ quan và mô sau vài tuần nhiễm Covid19. Người lớn tuổi có nguy cơ mắc bệnh Covid19 nặng và nguy cơ này tăng lên theo tuổi. Những người đang mắc các bệnh nền cũng có nguy cơ mắc bệnh nặng hơn như: bệnh tim, ung thư, bệnh phổi tắc nghẽn mạn tính, bệnh tiểu đường, thừa cân, béo phì, huyết áp cao...[2]

Về mặt chẩn đoán, RT-PCR được xem là xét nghiệm tiêu chuẩn để phát hiện bệnh nhân mắc Covid-19. Hình ảnh học cũng có vai trò quan trọng trong việc chẩn đoán và theo dõi các bệnh nhân này. $X$ quang ngực là phương tiện hình ảnh đầu tay đối với bệnh nhân nghi ngờ mắc Covid19. Tuy nhiên, X-quang ngực thường kém nhạy để phát hiện các bất thường phổi ở giai đoạn đầu của bệnh. Chụp cắt lớp vi tính (CT) được coi là phương pháp hình ảnh hiệu quả nhất để phát hiện các bất thường ở phổi, đặc biệt là trong giai đoạn đầu của bệnh. Tuy nhiển, trong tình hình 
dịch bùng phát diện rộng như hiên này, X-quang ngực vẫn là một công cụ hữu ích để chẩn đoán, theo dõi sự tiến triển nhanh chóng của bệnh Covid-19, nhất là ở những bệnh nhân nằm tại khoa chăm sóc đặc biệt. Lúc này, X-quang di động có thể dễ dàng chụp ngay tại giường bệnh, ít tốn kém, cơ động, tránh lây nhiễm, có thể chụp nhiều lần và dề đọc hơn so với phim $\mathrm{CT}$, khồng cần đến bác sĩ hình ảnh nhiều kinh nghiệm [3].

Tuy nhiên, kết quả $X$ quang ngực có thể rất khác biệt giữa các thây thuốc $X$-quang. Để chuẩn hóa kết quả, cần có một công cụ khách quan để các bác sĩ theo đó đánh giá và theo dõi. Hiện nay có một số hệ thống thang điểm có thể được sử dụng để đánh giá độ năng của tổn thương phổi trên X-quang và $C T$ ở bệnh nhân mắc Covid-19. Hệ thống thang điểm SARI (Severe Acute Respiratory Infection); hệ thống thang điểm RALE (Radiographic Assessment of Lung Edema); hệ thống thang điểm Brixia, được đề nghị bởi Borghesi và Maroldi năm 2020, được thiết kế dành cho những bệnh nhân đã xác định mắc Covid-19 [4]. Việt Nam hiện áp dụng Hệ thang điểm TTS trong chẩn đoán và điều trị Covid-19 theo Quyết định số 4689/QĐ-BYT, $6 / 10 / 2021[6]$.

Để tránh lây nhiễm trong việc chụp X-quang phổi, bệnh viện dùng hệ thống $X$-quang di động để tiến hành chụp cho bệnh nhân, đồng thời các bác sĩ điều trị phải đánh giá ngay tình trạng phổi của người bệnh để có biện pháp điều trị thích hợp, vì vậy việc huấn luyện cho bác sĩ điều trị đọc phim X-quang nhanh là điều cần thiết. Bệnh viện hiện áp dụng cả 2 hệ thống thang điểm đọc phim X-quang ngực TSS (Total Severity Score) và Brixia. Nghiên cứu này có mục tiêu so sánh 2 hệ thống thang điểm nêu trên trong hình ảnh $X$ quang ngực để đánh giá suy hô hấp cấp nặng do bênh COVID-19.

\section{II. ĐỐI TƯợNG VÀ PHƯƠNG PHÁP NGHIÊN CỨU}

Đối tượng nghiên cứu: Các bệnh nhân nhiễm Covid-19 đã có kết quả khẳng định bằng RT-PCR, nhập viện tại Khoa Nhiễm thuộc bệnh viện Nhật Tân, có làm đủ ít nhất 2 phim $X-$ quang, lúc vào viện và lúc ra viện hoặc chuyển viện. Đối tượng loại trừ: bệnh nhẩn < 18tuổi, các bệnh nhân chỉ còn 1 bên phổi.

Phương pháp nghiên cứu: Tiến cứu và mô tả có phân tích.

Thời gian và địa điểm nghiên cứu: Bệnh viện Nhật Tân được phép Sở Y tế An Giang cho phép thu dung điều trị bệnh nhân Covid-19 thuộc tầng 2 kể từ ngày 19/6/2021 cho đến nay. Công trình này bắt đầu nghiên cứu từ ngày 06/9/2021 cho đến hết ngày 13/11/2021.

Tổng số bênh nhân thu dung từ ngày mở khu điều trị Covid-19 cho đến hết ngày 13/11/2021 là 356 trường hợp. Bệnh ổn định xuất viện là 319, chiếm $89,6 \%$, số còn đang điều trị vào ngày 13/11/2021 là 10. Số ca chuyển viện Bệnh viện Đa khoa khu vực Châu Đốc (tầng 3 điều trị bệnh Covid-19) là $27 \mathrm{ca}$, trong số này tử vong là 14 trường hợp (tỷ lệ 51,9\%). Tỷ lệ tử vong Covid-19 nằm viện tai $B V$ Nhật Tân là 14/356 (3,93\%).

Cõ̃ mẫu và chọn mẫu: Mẫu nghiên cứu gồm 128 bệnh nhân có RT-PCR (+) và có đủ 2 phim Xquang phổi, chọn có chủ đích (lấy mẫu không xác suất) từ 356 bệnh nhân Covid-19 vào bệnh viện Nhật Tân điều trị. Tổng số 256 lần đọc phim, mỗi lần đọc cho điểm theo cả 2 hệ thang điểm.

Phương pháp đọc và tính điểm: Khoa Cận lâm sàng của bệnh viện Nhật Tân đã nghiên cứu phác đồ điều trị của Bộ Y Tế, trong đó có hướng dẫn cách đọc phim X-quang dùng thang TSS. Ngoài ra, cững nghiên cứu áp dụng cách đọc phim X-quang và tính điểm của các tác giả khác, trong đó có bảng điểm Brixia của Borghesi.A và CS [5]. Nhân viên đọc phim X-quang phổi gồm 2 ác sĩ (BS), một BS Chuyên khoa I Chẩn đoán hình ảnh và một Thac sĩ BS Chẩn đoán hình ảnh có lần lượt là 11 và 7 năm kinh nghiệm.

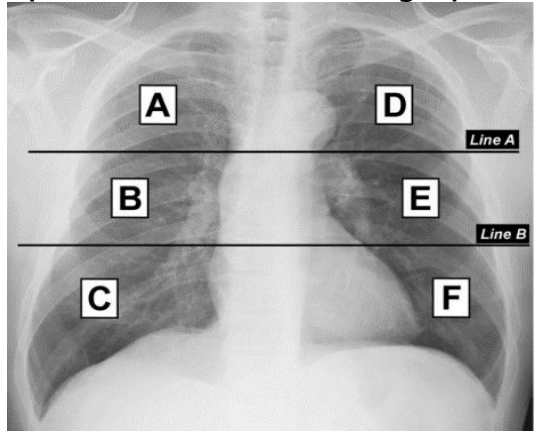

Hình 1: Chia phổi thành 6 vùng theo hệ thống Brixia

1. Hệ thônng thang điểm Brixia [5]

Bước 1: Phổi được chia thành 6 vùng theo mặt phẳng trán (tư thế sau trước hoặc trước sau):

- $A$ và $D$ : phía trên thành dưới của cung động mạch chủ (ĐMC);

- $B$ và $E:$ phía dưới thành dưới của cung ĐMC và trên thành dưới của tĩnh mạch phổi dưới phải

- C và F: phía dưới thành dưới tĩnh mạch phổi dưới phải.

Vì lý do kỹ thuật có thể sẽ khó xác định một số mốc giải phẫu. Khi đó, chia mỗi phế trường thành 3 phần bằng nhau. 


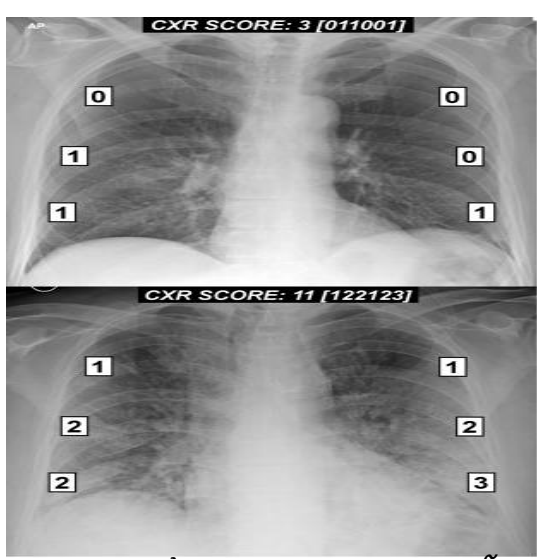

Hinh 2. Cho điểm từ o đến 3 cho mỗi khu vực

Bước 2: cho điểm (từ 0-3) cho mỗi vùng dựa trên tổn thương phổi, tổng18 điểm.

- 0 điểm: không có bất thường phổi

- 1 điểm: thấm nhâp mô kẽ

- 2 điểm: thấm nhập mô kẽ và phế nang (mô kẽ chiếm ưu thế)

- 3 điểm: thấm nhập mô kẽ và phế nang (phế nang chiếm ưu thế)

Các tổn thương khác như tràn dịch màng phổi, quai động mạch chủ bụng... không tính trong thang điểm.

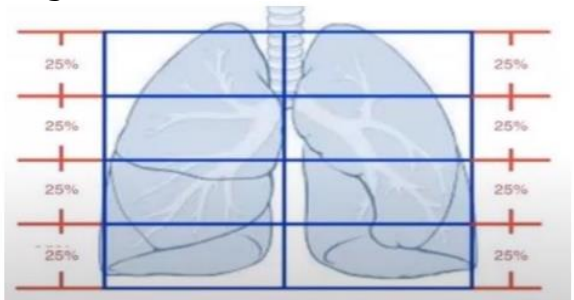

Hình 3. Thang điểm TSS trên X-quang

Theo Abo-Hedibah và cs [7] ở Ai Cập phân chia hệ điểm Brixia thành 4 nhóm theo X-quang phổi: bình thường 0 điểm, nhẹ từ 1-6 điểm, trung bình từ 7- 12 điểm, nặng từ 13-18 điểm.

2. Hệ thống thang điểm TSS (Total severity Score)[6]

Bảng 1. Thang điêm TSS

TSS (8 điếm) Chia môi bên phối làm 4 phần

bằng nhau, cho 1 đểm nếu có bất kỳ loai tổn

thương: dày kẽ, kính mờ, hoặc đông đặc...

\begin{tabular}{|c|c|}
\hline Mức độ & Điểm \\
\hline Nhẹ & $1-2$ \\
\hline Vừa & $3-6$ \\
\hline Nặng & $7-8$ \\
\hline
\end{tabular}

Xử lý thống kê: Dùng phần mềm IBM SPSS Statistics 29. Dùng crosstab để tính chỉ số tương hợp Kappa giữa 2 cách đo và so sánh mức độ cho điểm của 2 hệ cho điểm. Dùng biểu đồ Bland Altman để diễn tả sự tương hợp.

\section{KẾT QUẢ NGHIÊN CỨU}

Bảng 1. Sự tương hợp giữa TSS và Brixia của 2 BS đọc phim

\begin{tabular}{|c|c|c|c|}
\hline $\begin{array}{c}\text { Nội dung } \\
\text { so sánh }\end{array}$ & $\begin{array}{c}\text { Chỉ số } \\
\text { Kappa }\end{array}$ & $\begin{array}{c}\text { Sai số } \\
\text { chuẩn }\end{array}$ & $\begin{array}{c}\text { Độn } \\
\text { tương } \\
\text { hợp }\end{array}$ \\
\hline $\begin{array}{c}\text { So sánh TSS } \\
\text { giữa 2 BS }\end{array}$ & 0,734 & 0,035 & Tốt \\
\hline $\begin{array}{c}\text { So sánh Brixia } \\
\text { giữa 2 BS }\end{array}$ & 0,668 & 0,035 & Tốt \\
\hline $\begin{array}{c}\text { So sánh TSS và } \\
\text { Brixia của cả 2 BS }\end{array}$ & 0,584 & 0,023 & $\begin{array}{c}\text { Trung } \\
\text { bình }\end{array}$ \\
\hline
\end{tabular}

Nhận xét: Mối BS đọc phim cho 128 bệnh nhân ở 2 thời điểm (vào viện và ra viện hoặc chuyển viện) theo cả 2 thang điểm, với số lần đọc của mỗi BS là $128 \times 2=256$. Khi cùng chấm theo TSS và Brixia, cả 2 BS đều có chỉ số tương hợp "Tốt" với Kappa lần lượt là 0,734 và 0,668.

Để so sánh mức tương hợp với giữa 2 hệ TSS và Brixia, chúng tôi nhâp chung bảng điểm TSS và Brixia của 2 BS thành mỗi hệ điểm có 512 lần đọc $(256 \times 2)$.

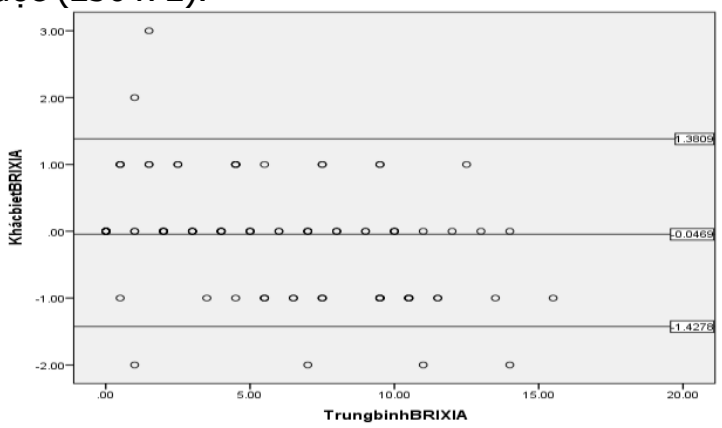

Hình 4. Biểu đồ Bland Altman về sự tương hợp giữa 2 bác sĩ $X$-quang đọc theo hệ TSS

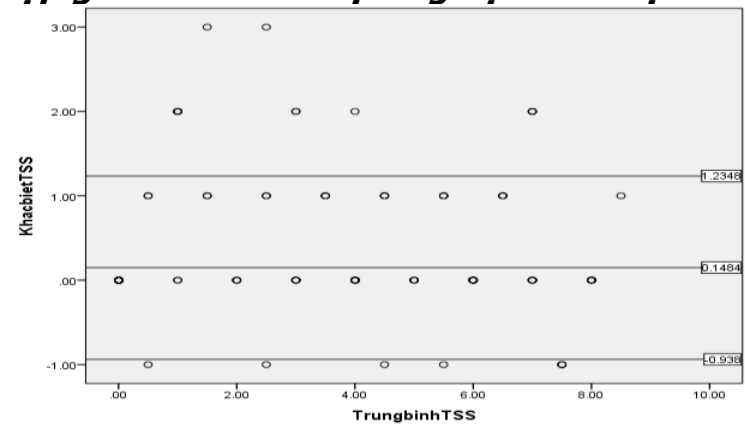

Hình 5. Biêu đồ Bland Altman về sự tương hợp giữa 2 bác si $X$-quang đọc theo hệ Brixia

Kết quả cho thãy tính tương hợp giữa 2 hệ chỉ ở mức "Trung bình" với Kappa bằng 0,584 . Tuy nhiên vì 2 hệ có số điểm tối đa khác nhau (TSS 8 và Brixia 18 điểm) nên không thể vẽ biểu đồ Bland Altman khi so sánh tương quan này. 
Bảng 2. So sánh 4 mức độ bênh của 2 hê thang điểm.

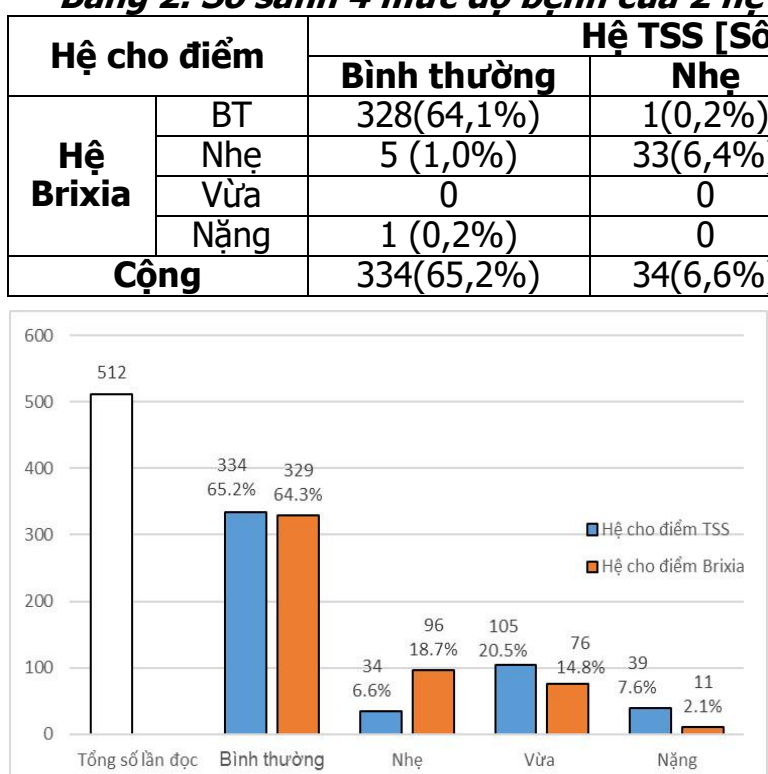

Hình 6. So sánh 4 mức độ bênh của 2 bảng điểm

Nhận xét: So sánh 2 hệ thang điểm TSS và Brixia gộp chung lần đọc của 2 BS, với số lần đọc mỗi BS thành 512 lần đọc. Mỗi hệ lại phân thành 4 mức độ bệnh: Bình thường (Covid-19 không triệu chứng); Nhẹ; Trung bình và Nặng. Qua phân tích bằng cách dùng bảng $2 \times 2$ (Bảng 2), có thể thấy số ca bình thường gần tương đương nhau $(64,1 \%$ và $65,2 \%)$. Với ca nhẹ hệ Brixia cao gấp 3 lần TSS (18,7\% so với $6,6 \%)$. Với ca vừa hệ Brixia thấp hơn TSS $(14,8 \%$ so với $20,5 \%)$. Còn với ca nặng hệ Brixia thấp hơn TSS khoảng 3 lần (2,1\% so với 7,6\%).

\section{BÀN LUÂ̂N}

Nghiên cứu của chúng tôi có 128 bệnh nhân nằm viện vì mắc Covid-19 đã được khẳng định bằng RT-PCR, mỗi bệnh nhân có đủ 2 phim Xquang phổi lúc vào và lúc bệnh nhân sắp ra viện hoặc chuyển viện lên bệnh viện chữa bệnh Covid-19 tầng 3, do Bệnh viện Nhật Tân chỉ chữa bệnh nhân Covid-19 thuộc tầng 2.

Bệnh nhân được chụp X-quang với máy Xquang di động. Bác sĩ điều trị (BS) phải đánh giá ngay tình trạng của bệnh nhẩn qua các dấu hiệu lâm sàng, xét nghiệm và cận lâm sàng. Muốn chẩn đoán nhanh và điều trị kịp thời, các $B S$ phải đọc nhanh phim X-quang phổi. Khoa cận lâm sàng của $B V$ Nhật Tân đã tiếp cận và hướng dẫn cho các BS cách đọc phim X-quang phổi, nhất là cách dùng hệ cho điểm TSS của Bộ Y tế [6], sau đó là hệ Brixia [8]. Trong nghiển cứu, 2 BS chuyên khoa chẩn đoán hình ảnh đọc theo cả 2 hệ cho điểm TSS và Brixia. Qua 256 lần đọc phim, mỗi lần đọc cho điểm cả 2 hệ, cả 2 BS đều có chỉ số tương hợp tốt với Kappa lần lượt là 0,734 và 0,668 (Bảng 1 ). Như vậy cả 2 BS tham gia nghiên cứu đã đọc phim X-quang ngực đáng tin cậy, ít có sai sót.

Để thử so sánh mức tương hợp với giữa 2 hệ cho điểm TSS và Brixia, chúng tôi nhập chung bảng điểm TSS và Brixia của cả 2 BS thành mối hệ điểm có 512 lần đọc $(256 \times 2)$. Tính tương hợp giữa 2 hệ này chỉ ở mức trung bình (Kappa là $0,584)$, một phần vì cả 2 hệ có số điểm tối đa khác nhau. Để tiếp tục đánh giá độ chính xác của mỗi hệ điểm, chúng tôi đã áp dụng thêm cách đánh giá theo phân chia mức độ bệnh (Bảng 2).

Theo hề cho điểm X-quang ngực TSS của Bộ $Y$ tế, chỉ có 3 mức độ bệnh: Nhe (1-2 điểm), Vừa (3-6 điểm) và Nặng (7-8 điểm). Không có mức độ "Bình thường", tức người mắc Covid-19 nhưng không có tổn thương trên X-quang ngực. Trên thực tế số "Bình thường" là một con số khá lớn, chiếm hơn phân nửa tổng số lần đọc phim X-quang (328 lần đọc, với 64,1\%). Do đó, chúng tôi thêm vào bảng điểm TSS mức độ "Bình thường" với ý nghĩa không có dấu hiệu bất thường trên phim X-quang ngực. Hệ cho điểm Brixia chúng tôi theo Abo-Hedibah và cs [7] vì ở Ai Cập cũng phân chia thành 4 nhóm như đã đề cập ở phần cách tiến hành nghiên cứu.

Trên cơ sở dùng bảng $2 \times 2$ để so sánh cách đánh giá của 2 hệ cho điểm (Bảng 2 và Hình 6), chúng tôi thấy người bệnh "Bình thường" giữa 2 hể Brixia và TSS gần tương đương nhau $(64,1 \%$ và $65,2 \%)$; người bệnh mức độ "Nhẹ": hệ Brixia cao gấp 3 lần hệ TSS $(18,7 \%$ so với $6,6 \%)$; người bệnh mức độ "Vừa": hệ Brixia thấp hơn TSS gần phân nửa $(14,8 \%$ so với $20,5 \%) ;$ người bệnh mức độ "Nặng": hệ Brixia thấp hơn TSS khoảng 3 lần ( $2,1 \%$ so với $7,6 \%)$. Nguyên nhân, theo chúng tôi, là do hệ Brixia phân tích chi tiết hình ảnh X-quang mà chỉ có BS chuyên khoa Xquang đủ kiến thức và kinh nghiệm có thể nhân biết và phân biệt, trong khi hệ TSS chỉ đánh giá theo tổn thương 8 ô mà không cân biết tổn thương đó là gì. Tuy nhiên cách đánh giá theo hê TTS lại có phần phù hợp cho hầu hết các BS lâm sàng ở các tuyến điêu trị hiện nay vì dễ tiến 
hành và có sẵn hướng dẫn của Bộ Y tế [6].

Qua nghiên cứu này, chúng tôi rút ra nhận xét bổ ích sau:

- Chẩn đoán tổn thương phổi bằng cách cho điểm có thể giúp đánh giá so sánh độ tương hợp tốt giữa các BS chuyên khoa Chẩn đoán hình ảnh và nên mở rộng áp dụng cho các BS lâm sàng khác đang thực hiện theo dõi và điều trị bệnh covid-19.

- Hệ cho điểm X-quang ngực Brixia rất thích hợp và hữu ích để phát hiện và đánh giá bệnh nhân Covid-19 mức độ "Nhẹ"; trong khi hệ TSS lại có ưu thế trong việc phát hiện, đánh giá bệnh nhân mức độ "Vừa" và "Nặng". Theo nghiên cứu của Agrawal và $\mathrm{Cs}$, thang điểm Brixia hầu hết các bệnh nhân tử vong đều có điểm số hơn 12; trong khi ở những bệnh nhân có điểm dưới 12 , hầu hết trong số họ đã được hồi phục và xuất viện [8].

\section{KẾT LUÂ̂N}

Đại dịch Covid-19 hiện vẫn còn phức tạp và $X$ quang phổi vẫn giữ vai trò quan trọng trong đánh giá tổn thương phổi và theo dõi diễn tiến của bệnh nhân các mức độ. Áp dụng hệ thống thang điểm trên $X$ quang phổi giúp các nhà lâm sàng và hình ảnh học có đánh giá nhanh và điều trị kịp thời. Thang điểm TSS có thể giúp các nhà lâm sàng đánh giá nhanh và dễ dàng hơn thang điểm Brixia. Nhưng khi dùng thang điểm TSS phải lưu ý đến việc bỏ sót các ca nặng độ 3 , độ 4 là những ca có nhiều nguy cơ tử vong.

\section{TÀI LIÊU THAM KHẢO}

1. WHO. Tracking SARS-CoV-2 variants. https://www.who.int/en/activities/tracking-SARSCoV-2-variants/

2. Kenneth McIntosh, Martin S Hirsch, Allyson Bloom, COVID-19: Clinical features. UpToDate. Oct 2021

3. Wasilewski PG, Mruk B, Mazur S, Szymczak GP, Sklinda KS, Walecki. COVID-19 severity scoring systems in radiological imaging - a review. Pol J Radiol 2020; 85: e361-e368

4. Taylor $E$, Haven $K$, Reed $P$, et al. A chest radiograph scoring system in patients with severe acute respiratory infection: a validation study. BMC Medical Imaging (2015) 15:61.

5. Borghesi $\mathbf{A}$, Ziglian $\mathbf{A}$, et al. Radiographic severity index in COVID-19 pneumonia: relationship to age and sex in 783 Italian patients. (C) Italian Society of Medical Radiology 13 April 2020.

6. Bộ Y tế. Hướng dẫn chẩn đoán và điều trị COVID19. 4689/QĐ-BYT, 6/10/2021

7. Abo-Hedibah SÁ, Tharwat N, Elmokadem AH. Is chest X-ray severity scoring for COVID-19 pneumonia reliable? Pol J Radiol. 2021; 86: e432-e439.

8. Nishant Agrawal et al. Brixia Chest X-ray Scoring System in Critically IIl Patients with COVID-19 Pneumonia for Determining Outcomes. Journal of Clinical and Diagnostic Research. 2021 Aug, Vol-15(8): OC15-OC17.

\title{
TÁC DỤNG KHÔNG MONG MUỐN CỦA HÓA TRI BỔ TRỢ PHÁC Đồ XELOX TRONG ĐIỀU TRI UNG THƯ ĐAI TRÀNG GIAI ĐOẠN II, III TẠI BÊ̂NH VIÊ̂N ĐÀ NẪNG
}

\author{
Đàm Minh Sơn*, Lê Quốc Tuấn*, Nguyễn Văn Hiếu** \\ TÓM TẮT \\ Mục tiêu: Mô tả một số đặc điểm lâm sàng, cận \\ lâm sà̀ng bênh nhân ung thư đại tràng giai đoan II, İI \\ tại bệnh viện Đà Nẵng và đánh giá tác dụng không \\ mong muốn của hóa trị bổ trớ phác đồ XELOX trong \\ nhóm bệnh nhân nghiên cứu. Đối tượng và phương \\ pháp: Ǹghiên cứu mô tả lâm sàng có theo dôi dọc \\ trên 66 bệnh nhân được chẩn đoán ung thư đại tràng \\ giai đoạn II nguy cơ cao và giai đoạn III điều trị tại \\ Bệnh viện Đà Nằng từ tháng 6/2017 - 6/2020. Kềt \\ *Bệnh viện Đà Nẵng. \\ **Trường đại học y Hà Nội \\ Chiu trách nhiệm chính: Đàm Minh Sơn \\ Email: minhson285@gmail.com \\ Ngày nhận bài: 26.10.2021 \\ Ngày phản biện khoa học: 27.12.2021 \\ Ngày duyệt bài: 4.01.2022 \\ quả: Tuổi trung bình của bệnh nhân là $59.98 \pm 10.33$, \\ nhóm tuổi từ $50-59$ và $60-69$ chiếm tỷ lệ cao nhất là \\ $34.8 \%$. Vị trí u hay gặp nhất là đại tràng góc gan \\ $22.7 \%$, đai tràng sigma $37.9 \%$, khối u biêt hóa vừa \\ chiếm tỷ lệ $74.2 \%$. Đa phần độc tính của điều trị đều \\ ở độ 1-2, tỷ lệ độc tính độ 3-4 về huyết học, tăng men \\ gan, hội chứng bàn tay bàn chân, độc tính thân kinh \\ ngoại biên chiếm tỷ lệ 3\%-4.5\%. Kểt luận: Phác đồ \\ XELOX an toàn trong điều trị bổ trợ ở nhóm bệnh \\ nhân nghiên cứu với các tác dụng khồng mong muốn \\ ở mức đô nhe. \\ Tư khóa: Ung thư đại tràng, XELOX.

\section{SUMMARY} \\ SIDE EFFECTS OF ADJUVANT CHEMOTHERAPY \\ USING XELOX REGIMEN FOR COLON CANCER \\ STAGE II,III AT DA NANG HOSPITAL \\ Objectives: Describe some clinical and subclinical \\ characteristics of patients with stage II, III colon
}

